\title{
188. PRIMERA CITA DEL ENDEMISMO IBÉRICO ALLIUM SCHMITZII COUT. (LILIACEAE) EN ANDALUCÍA (ESPAÑA)
}

\author{
Javier LÓPEZ TIRADO ${ }^{1 *}$, Azucena NÚÑEZ ÁLVAREZ ${ }^{1}$, Rafael OBREGÓN ROMERO², \\ Manuel MORENO GARCÍA ${ }^{3}$ y Pablo J. HIDALGO FERNÁNDEZ ${ }^{1}$
}

Recibido el 7 de septiembre de 2015, aceptado para su publicación el 6 de octubre de 2015

First record of the Iberian endemism Allium schmitzii Cout. (Liliaceae) in Andalusia (Spain)

Palabras clave. Corología, Liliaceae, Allium schmitzii, primera cita, Andalucía, Península Ibérica.

Key words. Chorology, Liliaceae, Allium schmitzii, first record, Andalusia, Iberian peninsula.

Allium schmitzii es una liliácea endémica de la Península Ibérica. Al igual que el resto de especies del género, $A$. schmitzii es una planta herbácea bulbosa. Presenta una inflorescencia umbeliforme esférica o hemisférica, filamentos estaminales simples y hojas cilíndricas, fistulosas, glabras. La espata está compuesta por dos piezas subiguales más cortas que la umbela y el bulbo de forma fusiforme está envuelto por una túnica coriácea, lisa, rojiza. Aparte de estos caracteres morfológicos, su especificidad ecológica ayuda también a su identificación, ya que habita en las grietas de rocas de los márgenes y lechos secos de ríos y arroyos (Stearn, 1980; Pastor \& Valdés, 1983; Aedo, 2013) como se puede apreciar en la figura 1. Es una especie catalogada como vulnerable a nivel estatal (Bañares et al., 2008; Moreno, 2011) y de interés especial en Extremadura (Anónimo, 2004).

Este taxón fue descrito por Coutinho (1897) en Portugal. Más tarde, Stearn (1980) cita también esta especie para Portugal. Es precisamente en ese mismo año cuando se da a conocer por primera vez para España, concretamente de la provincia de Salamanca (Rico Hernández, 1980). Más recientemente se han encontrado otras poblaciones bastante disyuntas en la geografía española, como son aquellas de Álava, Burgos, Ciudad Real, Soria y Zamora (Valdés Franzi, 1983; García Río, 1998; Aedo, 2013), quedando excluida de la flora de Navarra (Lorda et al., 2011).

En el presente trabajo se da a conocer la primera población de $A$. schmitzii en Andalucía:

Allium schmitzii Cout.

Córdoba. Córdoba: Río Guadiato [30SUH3102], 255 m, 28.VII.2015, J. López Tirado (COFC 61984).

La población más cercana es la presente en el río Montoro, en el Parque Natural del Valle

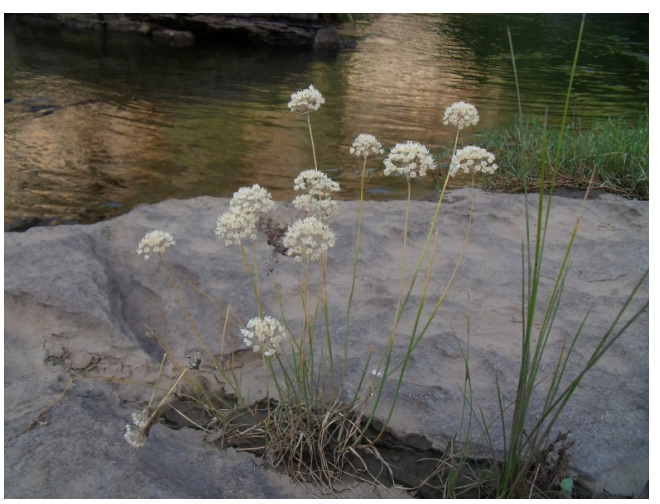

Figura 1. Hábitat natural de A. schmitzii en el río Guadiato (Córdoba). 
de Alcudia y Sierra Madrona (Ciudad Real), que dista unos $102 \mathrm{~km}$ en línea recta. Se ha realizado un conteo en la nueva población de Córdoba con un resultado de 1443 individuos maduros formando grupos compactos y más o menos dispersos entre ellos, ocupando un rodal de unos $184 \mathrm{~m}^{2}$ aproximadamente. Con estos datos y siguiendo los criterios UICN (2001) este taxón debe ser considerado hasta el momento como casi amenazado (NT) en Andalucía. Es destacable que el alto grado de inaccesibilidad al río Guadiato hace que esta especie se encuentre aparentemente exenta de algún tipo de alteración y contaminación por parte del ser humano. La ecología donde se desarrolla $A$. schmitzii se repite frecuentemente en las orillas del río, por lo que no se descarta la existencia de otras poblaciones.

\section{BIBLIOGRAFÍA}

AEDO, C. -2013-Allium L. in CASTROVIEJO, S. et al. (eds.) Flora Iberica Vol. XX: 220-273. C.S.I.C., Madrid.

ANÓNIMO -2004-Especies Protegidas de Extremadura: Flora, Consejería de Agricultura y Medio Ambiente. Junta de Extremadura.

BAÑARES, A., G. BLANCA, J. GÜEMES, J.C. MORENO \& S. ORTIZ (eds.) -2008- Lista roja 2008 de la flora vascular española. Dirección General de Medio Natural y Política Forestal (Ministerio de Medio Ambiente, y Medio Rural y Marino) - SEBICOP, Madrid.

COUTINHO, A.X. -1897- As liliaceas de Portugal. Contribuições para o estudo da flora portugueza. Boletim Sociedade Broteriana Vol. XIII: 71-129.

GARCÍA RÍO, R. -1998- Doce plantas del conjunto montañoso de Sierra Madrona. Anales Jard. Bot. Madrid 56(2): 402-404.

LORDA, M., J. PERALTA, A. BERASTEGI \& D. GÓMEZ -2011- Síntesis de la flora vascular de Navarra. Actes del IX Col-loqui Internacional de Botánica Pirenaico-cantábrica a Ordino, Andorra: 251-258.

MORENO, J.C. -2011- Lista Roja de la Flora Vascular Española. Actualización con los datos de la Adenda 2010 al Atlas y Libro Rojo de la
Flora Vascular Amenazada. Dirección General de Conservación de la Naturaleza y Sociedad Española de Biología de la Conservación de Plantas. Madrid. 46 pp.

PASTOR, J. \& B. VALDÉS -1983- Revisión del género Allium (Liliaceae) en la Península Ibérica e Islas Baleares. Publicaciones de la Universidad de Sevilla. 179 pp.

RICO HERNÁNDEZ, E. -1980- Aportaciones a la flora salmantina. Anales Jard. Bot. Madrid 36: 245-255.

STEARN, W.T. -1980- Allium L. in T.G. TUTIN, V.H. HEYWOOD, N.A. BURGES, D.H. VALENTINE, S.M. WALTERS \& D.A. WEBB (eds.). Flora Europaea Vol. 5: 49-69. Great Britain: Cambridge University Press.

UICN -2001- Categorías y Criterios de la Lista Roja de la UICN: Versión 3.1. Comisión de Supervivencia de Especies de la UICN. UICN, Gland, Suiza y Cambridge, Reino Unido. ii + $33 \mathrm{pp}$.

VALDÉS FRANZI, A. -1983- Algunas plantas interesantes de la Sierra de Gata (Cáceres). Studia Botanica 2: 195-200.

Dirección de los autores. 'Departamento de Biología Ambiental y Salud Pública. Facultad de Ciencias Experimentales, Campus de El Carmen, Universidad de Huelva, 21071 (Huelva). ${ }^{2}$ Departamento de Botánica, Ecología y Fisiología Vegetal. Edificio Celestino Mutis, Campus de Rabanales, Universidad de Córdoba, 14071 (Córdoba). ${ }^{3}$ IFAPAAlameda del Obispo, avda. Menéndez Pidal s/n, 14004 (Córdoba). *Autor para correspondencia: javier.lopez@dbasp. uhu.es 